\title{
Overexpression of LASS2 inhibits proliferation and causes G0/G1 cell cycle arrest in papillary thyroid cancer
}

\author{
Feng Zeng ${ }^{1 \dagger}$, Liangliang Huang ${ }^{1 \dagger}$, Xiaoming Cheng ${ }^{1}$, Xiaoli Yang ${ }^{2,3}$, Taolang Li ${ }^{1}$, Guoli Feng ${ }^{1}$, Yingqi Tang ${ }^{1}$
} and Yan Yang $2,3^{*}$ (D)

\begin{abstract}
Background: The aim of this study was to investigate the role of LAG1 longevity-assurance homologue 2 (LASS2) in papillary thyroid cancer (PTC).

Methods: Immunohistochemistry staining was conducted to explore the expression levels of LASS2 in PTC tissues and adjacent normal thyroid tissues and nodular goiter tissues. Western blotting and RT-qPCR were performed to explore the expression levels of LASS2 in three PTC cell lines (TPC-1, K1, BCPAP). An Adv-LASS2-GFP recombinant adenovirus vector was constructed and transduced into BCPAP cells. Then CCK-8 assay, colony formation assay, cell cycle distribution, and apoptosis were performed. Western blotting was used to examine the expression of p21, cyclin D1, cyclin-dependent kinase 4, p53 and p-p53.

Results: LASS2 was downregulated in PTC tissues compared with adjacent thyroid tissues or nodular goiter tissues. In addition, the expression of LASS2 was found to be associated with TNM stage and lymph node metastasis. BCPAP cells expressed the lowest LASS2 compared to TPC-1 cells or K1 cells. Overexpression of LASS2 significantly inhibited proliferation, promoted apoptosis and caused G0/G1 cell cycle arrest in BCPAP cells. Furthermore, overexpression of LASS2 significantly increased the expression of p21, inhibited the expression of cyclin D1 and cyclin-dependent kinase 4, and increased the expression of p-p53, but did not effect the expression of p53 in BCPAP cells.
\end{abstract}

Conclusion: Our findings indicate that overexpression of LASS2 inhibits PTC cell proliferation, promotes apoptosis and causes G0/G1 cell cycle arrest via a p53-dependent pathway. Thus, LASS2 may serve as a novel biomarker in PTC.

Keywords: LAG1 longevity-assurance homologue 2, Papillary thyroid cancer, Proliferation, Cell cycle

\section{Background}

Thyroid cancer is the most common endocrine tumor, accounting for $96 \%$ of all endocrine neoplasms and $66.8 \%$ of all cases of endocrine tumor-related deaths [1]. In the United States, the incidence of thyroid cancer is increasing, while that of several head and neck tumors is decreasing [2]. Interestingly, the increase in the incidence

\footnotetext{
*Correspondence: yy623yy@163.com

${ }^{\dagger}$ Feng Zeng and Liangliang Huang contributed equally to this work

${ }^{3}$ Department of Clinical Laboratory, Affiliated Hospital of ZunYi Medical College, 149 Dalian Road, Zunyi 563003, Guizhou, People's Republic of China

Full list of author information is available at the end of the article
}

of thyroid cancer is mainly due to increased cases of papillary thyroid cancer (PTC), while the increase in follicular or medullary subtypes is significantly less prominent [3]. It was previously demonstrated that the molecular mechanisms of thyroid cancer mainly involve genetic and epigenetic changes, such as gene mutations, leading to the activation of oncogenes and the inactivation of tumor suppressor genes [4]. With the development of molecular biology technology, researchers have identified a variety of oncogenes and tumor suppressor genes that may serve as molecular markers in thyroid tumors, such as BRAF, PTEN, CRABP1, C1QL1 and LCN2 [57]. In recent years, there has been a general consensus regarding molecular markers as potential diagnostic and

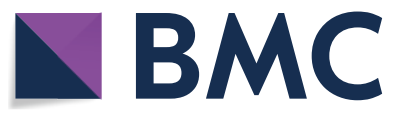

(c) The Author(s) 2018. This article is distributed under the terms of the Creative Commons Attribution 4.0 International License (http://creativecommons.org/licenses/by/4.0/), which permits unrestricted use, distribution, and reproduction in any medium, provided you give appropriate credit to the original author(s) and the source, provide a link to the Creative Commons license, and indicate if changes were made. The Creative Commons Public Domain Dedication waiver (http://creativecommons.org/ publicdomain/zero/1.0/) applies to the data made available in this article, unless otherwise stated. 
prognostic tools for thyroid cancer. Krishnamurthy et al. [8] reported that the incorporation of novel molecular markers in patients with conventional PTC is of great significance in diagnosis and treatment individualization. However, the molecular mechanisms that have already been identified are unable to explain $100 \%$ of the cases.

LAG1 longevity assurance homolog 2 (LASS2), also referred to as ceramide synthase 2 (CerS2), was designated as LASS2 by researchers at Shanghai Fudan University in 2001 [9]. LASS2 belongs to the family of mammalian CerS genes involved in sphingolipid metabolism, and is known as a tumor metastasis suppressor $[10,11]$. Previous studies have demonstrated that the LASS2 gene is associated with the proliferation, invasion, metastasis and apoptosis of multiple cancer cells, such as bladder, prostate, breast and liver cancer cells [12-15], and is associated with worse prognosis of meningiomas and bladder cancer $[16,17]$. Therefore, it may represent a potential biomarker for several cancers. Jin et al. [18] reported decreased formation of the cyclindependent kinase (CDK)4/cyclin D1 complex following partial hepatectomy in liver-specific LASS2 knockout mice, indicating that it may play a role in cell cycle regulation. In addition, Su et al. [19] reported that overexpression of LASS2 inhibited cell proliferation by mediating the induction of G0/G1 cell cycle arrest in 293 and 293T cells, while Fan et al. [20] revealed that the overexpression of LASS2 had no effect on cell cycle progression in the breast cancer cell line MCF-7/ADR. However, the potential molecular mechanism underlying LASS2mediated biological behavior in various types of cancer remains elusive. Previous studies have focused on the regulation of LASS2 in the tumor microenvironment, and revealed that it may inhibit cancer invasion and metastasis by regulating V-ATPase activity and extracellular $\mathrm{H}^{+}$concentration [12]. However, to the best of our knowledge, there has been no report investigating the role of LASS2 in thyroid cancer to date.

The aim of the present study was to analyze the role of LASS2 in thyroid cancer using patient samples and the PTC cell line BCPAP, in order to determine whether overexpression of LASS2 inhibits PTC cell proliferation and elucidate the underlying mechanism, hoping to identify a new potential molecular marker in this type of cancer.

\section{Methods}

\section{Patients and tissue samples}

Thyroid tissues were obtained from 97 patients at the time of initial surgery at the Medical Center of Breast and Thyroid Disease of the Affiliated Hospital of Zunyi Medical College (Guizhou, China) and stored at $-80^{\circ} \mathrm{C}$. The study protocol was approved by the Ethics Committee of the Affiliated Hospital of Zunyi Medical College, and human thyroid tissues were obtained following provision of informed consent by the patients. All tissue samples were examined and the diagnosis was confirmed by two pathologists.

\section{Cell lines and cell culture}

The BCPAP, TPC-1 and $\mathrm{K} 1$ cell lines were provided by Stem Cell Bank, Chinese Academy of Sciences (Shanghai, China) and cultured in RPMI-1640 supplemented with $10 \% \mathrm{FBS}$ and incubated at $37^{\circ} \mathrm{C}$ in a $5 \% \mathrm{CO}_{2}$ atmosphere.

\section{Reverse transcription-quantitative polymerase chain reaction (RT-qPCR) analysis}

Total RNA was extracted from BCPAP cells using TRIzol reagent (Takara Bio Inc., Otsu, Japan), according to the RNAiso Plus kit instructions. Total RNA was reversetranscribed to cDNA using Prime ScriptTMRT reagent kit (Takara Bio Inc.). RT-qPCR was performed using SYBR ${ }^{\circledR}$ Premix Ex TaqTM II (Takara Bio Inc.). GAPDH was used as endogenous control. The primers for RTqPCR were as follows: LASS2: forward, $5^{\prime}$-ATCGTCTTC GCCATTGTT- $3^{\prime}$ and reverse, 5'-CGGTCACTGCGT TCATCT-3'; GAPDH: forward, 5'-GGAGCGAGATCC CTCCAAAAT- $3^{\prime}$ and reverse, 5'-GGCTGTTGTCAT ACTTCTCATGG-3' (197 bp). The levels of LASS2 were analyzed by the $2^{-\Delta \Delta \mathrm{Ct}}$ method.

\section{Immunohistochemistry}

Paraffin-embedded specimens were cut into $3-\mu \mathrm{m}$ sections for hematoxylin and eosin (H\&E) staining and immunohistochemistry (IHC). The assays were performed as previously described [16], and the primary antibody used was anti-LASS2 at a dilution of 1:200 (Abcam, Cambridge, UK).

The scoring of LASS2 expression was also performed as previously described [16]. The intensity distribution (ID) score for LASS2 was evaluated by the sum of the percentage of positive cells $(0:<5 \% ; 1: 5-25 \%$; $2: 26-50 \%$; 3 : 51-75\%; and 4: 76-100\%) and the staining intensity was graded from 0 to 3 ( 0 , negative; 1 , weak; 2 , moderate; and 3 , strong). ID scores $\geq 6$ were considered to reflect high expression, and those $\leq 4$ low expression.

All histological stainings were evaluated by two pathologists, and the scores were calculated by two observers.

\section{Construction of Adv-LASS2-GFP recombinant adenovirus vector}

The LASS2 recombinant eukaryotic expression of LASS2-GFP (as insert segment) and pShuttle-CMV recombinant shuttle vector, were constructed and digested with HindIII/NotI, respectively, and then ligated with T4 DNA ligase. Subsequently, transformed plasmids 
were extracted and sequencing was performed to obtain pShuttle-LASS2-GFP recombinant shuttle plasmid. Next, the pAdxsi vector and pShuttle-LASS2-GFP were separately digested with I-Ceul and I-Scel, then ligated and transformed. To obtain pAdxsi-LASS2-GFP viral plasmid, extensive extraction of the viral plasmids was performed, followed by packaging, collection and amplification. Finally, a recombinant Adv-LASS2-GFP was obtained, with a titer of $1.2 \times 10^{10} \mathrm{PFU} / \mathrm{ml}$.

\section{Western blotting}

The BCPAP cells were lysed with RIPA lysis buffer (1\% NP-40, 0.1\% SDS, $50 \mathrm{mM}$ DTT) containing protease inhibitor cocktail on ice. After centrifugation, the supernatant was collected in $1.5-\mathrm{ml}$ centrifuge tubes. The cell lysate was loaded on $10 \%$ sodium dodecyl sulfate polyacrylamide (SDS-PAGE) gels after being heated at $100{ }^{\circ} \mathrm{C}$ for $3 \mathrm{~min}$ for denaturation and then transferred onto PVDF membranes. The membranes were blocked with $5 \%$ skimmed milk at $37{ }^{\circ} \mathrm{C}$ for $2 \mathrm{~h}$. The blocked membranes were washed with PBST buffer 2-3 times and incubated with the primary antibodies for $2 \mathrm{~h}$ at room temperature. After the membranes were washed four times with PBST buffer, they were incubated with a corresponding secondary antibody in PBST buffer at $4{ }^{\circ} \mathrm{C}$ overnight, followed by washing four times with PBST. The blots were detected using Enhanced Chemiluminescence Detection kit (KGP116, KeyGen BioTECH, Jiangsu, China). The primary antibodies used in the experiment were anti-p53 (ab31333, 1:1000), anti-CDK4 (ab137675, 1:2000), anti-cyclin D1 (ab137875, 1:5000) and p21 (ab109520, 1:1000), all purchased from Abcam; Antip-p53 (\#9284, 1:1000) was purchased from CST; AntiGAPDH (SC-365062, 1:800) was purchased from Santa Cruz Biotechnology, Inc. (Dallas, TX, USA). The secondary antibody used in the experiment were: goat anti-rabbit, goat anti-mouse IgG (1:4000 for both).

\section{Subcellular localization of LASS2 by confocal laser scanning microscopy in BCPAP cells}

BCPAP cells were transfected with Adv-LASS2-GFP for $48 \mathrm{~h}$. After washing three times with PBS, the cells were fixed with $4 \%$ paraformaldehyde for $30 \mathrm{~min}$. Autofluorescence from the LASS2 protein was observed under a confocal microscope (LSM510; Carl Zeiss AG, Oberkochen, Germany) with excitation at $488 \mathrm{~nm}$ and a $525-\mathrm{nm}$ GFP filter. Images were acquired at a $\times 200$ magnification.

\section{Cell proliferation assay}

For the proliferation assay, BCPAP cells were treated with Cell Counting Kit- 8 reagent (Beyotime Institute of
Biotechnology, Shanghai, China), according to the manufacturer's instructions. Absorbance at $450 \mathrm{~nm}$ was measured on a microplate reader at the designated time points after treatment. The assay was performed in triplicate.

\section{Colony formation assay}

For the colony formation assay, the transfected cells were plated at 1000 cells/well in a 6-well plate and incubated for 2 weeks. The colonies were fixed and then stained with $0.5 \%(\mathrm{w} / \mathrm{v})$ crystal violet solution for $30 \mathrm{~min}$ at room temperature. The colonies were photographed and counted. The assay was performed in triplicate.

\section{Cell cycle analysis}

BCPAP cells transfected with Adv-GFP or Adv-LASS2GFP were harvested $48 \mathrm{~h}$ after culture, washed with PBS and fixed in $500 \mu \mathrm{l}$ of $75 \%$ cold ethanol at $4{ }^{\circ} \mathrm{C}$ overnight, and then washed with PBS, stained by $100 \mu \mathrm{l}$ propidium iodide $\left(3.8 \times 10^{-2}\right.$ sodium citrate, $\left.\mathrm{pH} 7.0\right)$ containing RNase A $(10 \mathrm{mg} / \mathrm{ml})$ for $30 \mathrm{~min}$ in the dark at $37^{\circ} \mathrm{C}$. The cell populations in the G0-G1, S and G2-M phases were measured by flow cytometry (Beckman Coulter, Inc., Brea, CA, USA), and analyzed using ModiFit software. All the samples were assayed in triplicate.

\section{Annexin-V APC/7-AAD double-staining to detect apoptosis} Following transfection with Adv-GFP or Adv-LASS2GFP, BCPAP cells were harvested with $0.25 \%$ trypsin (without EDTA). Complete medium was added to the cells to inactive trypsin, and the cells were washed twice with PBS (centrifugation at $800 \mathrm{~g}, 5 \mathrm{~min}$ ). The cells were subsequently resuspended in $500 \mu \mathrm{l}$ of binding buffer. After $5 \mu \mathrm{l}$ of Annexin V-APC was added and mixed well, $5 \mu \mathrm{l}$ of 7 -AAD was added and mixed well. The cells were incubated at room temperature for $15 \mathrm{~min}$ in the dark, then immediately analyzed using a flow cytometer (FACSCalibur, BD Biosciences, San Diego, CA, USA) using CellQuest software.

\section{TUNEL assay}

The amount of DNA fragmentation was determined using a commercial BIOTIN labeling dUTP TUNEL kit (KeyGen BioTECH, Jiangsu, China) according to the instructions of the manufacturer. Briefly, BCPAP cells on the slides were washed with PBS three times, and then fixed with $4 \%$ paraformaldehyde for $30 \mathrm{~min}$, permeabilized with $1 \%$ Triton $\mathrm{X}-100$ at room temperature for $15 \mathrm{~min}$, and then treated with $3 \% \mathrm{H}_{2} \mathrm{O}_{2}$ containing methanol for $15 \mathrm{~min}$. After the enzymatic reaction, cells were washed with PBS, incubated with a mixture of TdT solution and fluorescein isothiocyanate dUTP solution at 
$37^{\circ} \mathrm{C}$ for $60 \mathrm{~min}$ in a humidified chamber, then incubated with $100 \mu$ l streptavidin-horseradish peroxidase at $37^{\circ} \mathrm{C}$ for $30 \mathrm{~min}$ in a humidified chamber. After washing with PBS, the cells were stained with DAB solution, followed by counterstaining with hematoxylin, and observed under a light microscope. Cells with brown granules in the nuclei were considered as TUNEL-positive. Cells were counted (high-power field, magnification $\times 200$ ) under an optical microscope (Olympus, Tokyo, Japan) to determine the mean percentage of positive cells.

\section{Statistical analysis}

All statistical analyses were performed using SPSS 21.0 software (SPSS version 21.0., IBM Corp., Armonk, NY, USA). GraphPad Prism 5 (GraphPad Software Inc., San Diego, CA, USA) was used for graphs. The Chi squared test or Fisher's exact test was used to evaluate the association between clinicopathological characteristics and LASS2 expression. Student's t-test was performed to analyze differences between groups. All values represent at least three independent experiments and are expressed as the mean \pm standard deviation. $P<0.05$ was considered to indicate statistically significant differences.

\section{Results}

\section{Expression of LASS2 in thyroid tissues}

To explore the LASS2 expression in thyroid tissues, IHC was performed in 117 paraffin-embedded specimens, including 60 PTC, 20 adjacent thyroid tissues and 37 nodular goiters. LASS2 immunoreactivity was mainly detected in the cytoplasm and nucleus (Fig. 1).

To validate the expression LASS2 in different thyroid tissues, immunostaining was performed by semi-quantitative analysis and represented by an ID score (Table 1). The results revealed that the number of cases scoring $\geq 6$ was $14(14 / 20,70.00 \%)$ in adjacent thyroid tissues, 21 $(21 / 37,56.76 \%)$ in nodular goiter tissues, and $23(23 / 60$, $38.33 \%$ ) in PTC tissues. These results indicate that LASS2 expression was decreased in PTC.

\section{Correlations between LASS2 expression and clinicopathological parameters}

To determine whether LASS2 expression is associated with tumorigenesis and progression of PTC, we investigated the correlations between this gene and clinicopathological parameters (Table 2). It has been observed that the LASS2 expression level was positively correlated with TNM stage and lymph node metastasis (LNM) $(P=0.045$ and 0.001 , respectively). However, there were no observed correlations between LASS2 expression and patient sex, age, tumor size or location (all $P>0.05$ ).
The expression and subcellular localization of LASS2 in PTC cell lines

To investigate the biological function of LASS2, we detected its expression in three PTC cell lines (TPC-1, K1, BCPAP) (Fig. 2a). The results showed that BCPAP cells expressed the lowest LASS2 compared to TPC-1 cells or K1 cells. Then we successfully overexpressed LASS2 in BCPAP cells using adenovirus vectors (Fig. 2b). We further examined the subcellular distribution of LASS2 in BCPAP cells using a confocal laser scanning microscope. Consistent with the results of $\mathrm{IHC}$, the results demonstrated that LASS2 mainly localized to the cytoplasm and nucleus, with a lower distribution to the cell membrane (Fig. 2c).

\section{Overexpression of LASS2 inhibits the proliferation of BCPAP cells}

In order to determine the role of LASS2 in BCPAP cells, CCK-8 and colony formation assays were performed. It was clearly demonstrated that upregulated LASS2 expression effectively inhibited BCPAP cell proliferation and colony formation compared with the corresponding control cells (Fig. 2d, e, both $P<0.05$ ).

\section{Overexpression of LASS2 causes cell cycle arrest at the G0/ G1 phase in BCPAP cells}

We used cell-based cytometry and western blotting to evaluate whether LASS2 regulates the cell cycle progression in BCPAP cells treated with Adv-GFP or AdvLASS2-GFP. LASS2 induced arrest at the G0/G1 phase in BCPAP cells after $48 \mathrm{~h}$ of treatment (Fig. $3 \mathrm{a}, \mathrm{b}, P<0.01$ ); the percentage of cells in the G0/G1 phase in the $\mathrm{NC}$, Adv-GFP and Adv-LASS2-GFP groups was 54.01, 54.13 and $71.94 \%$, respectively.

Furthermore, it was demonstrated that LASS2 significantly upregulated p21, whereas it downregulated CDK4 and cyclin D1 (Fig. 3c, all $P<0.05$ ). However, the p53 protein, which regulates the p21 gene [21], was not found to be significantly up- or downregulated (Fig. 3c, $P>0.05$ ). Furthermore, in order to evaluate the role of p53 better, we detected the expression of p-p53 and found it was efficiently increased (Fig. $3 \mathrm{~d}, P<0.001$ ), pointing to a p53-dependent pathway for p21 activation in cell cycle progression and $\mathrm{G0} / \mathrm{G} 1$ phase arrest.

\section{Overexpression of LASS2 promotes apoptosis of BCPAP cells}

As shown in Fig. 4, overexpression of LASS2 significantly affected the apoptosis of BCPAP cells. An Annexin V-APC/7-AAD kit was used for these assays, and the results indicated that the apoptotic index of 


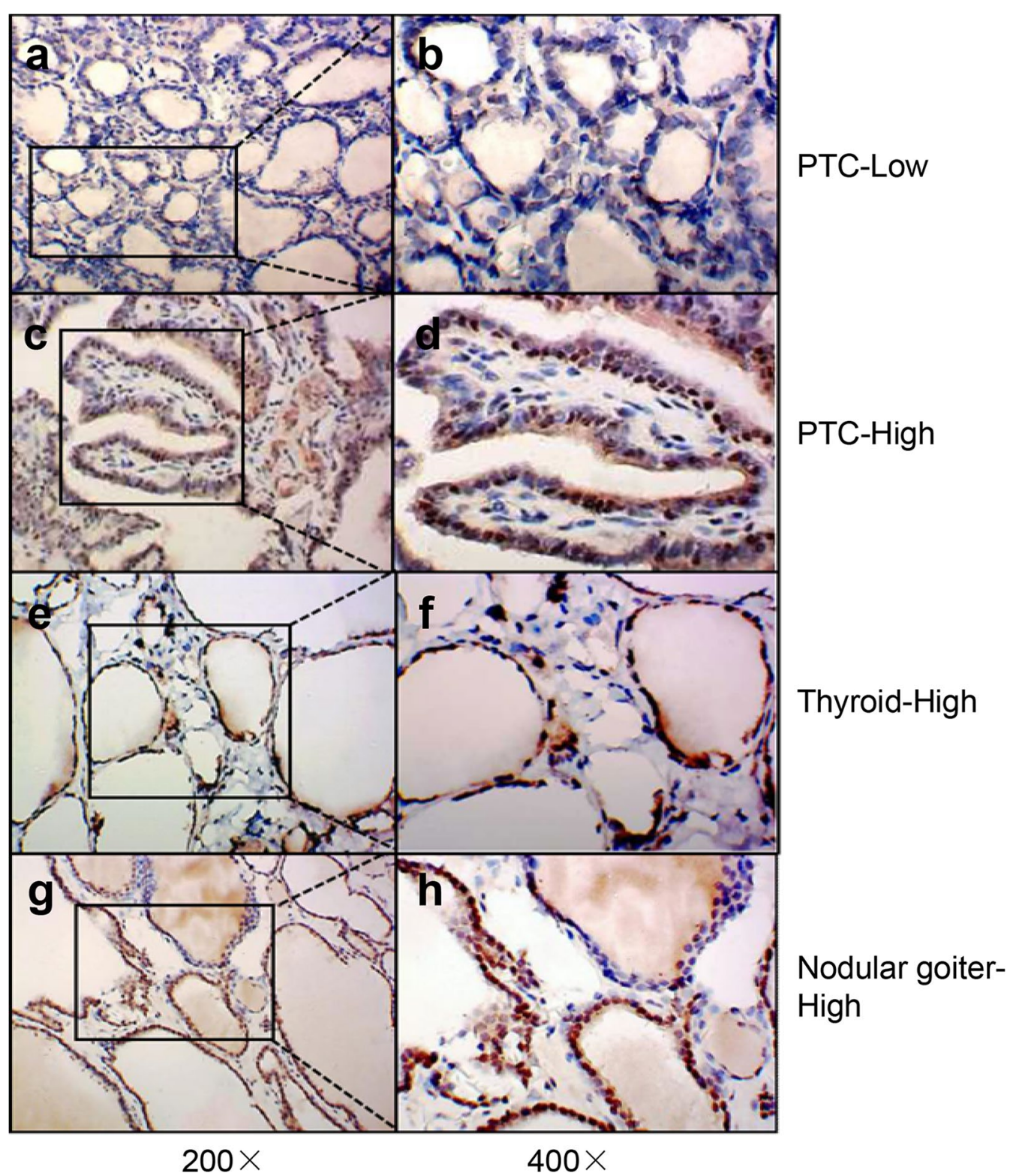

Fig. 1 Immunohistochemical analysis of LASS2 expression in PTC, adjacent thyroid tissues and nodular goiter. a-d Representative immunohistochemical staining patterns for LASS2 in PTC. Its protein expression level was graded as low, high. e and $\mathbf{f}$ Representative immunohistochemical staining patterns for LASS2 in adjacent thyroid tissues. Its protein expression level was graded as high. $\mathbf{g}$ and $\mathbf{h}$ Representative immunohistochemical staining patterns for LASS2 in nodular goiter. Its protein expression level was graded as high. The LASS2 expression was located in cytoplasm and/or nucleus. Left and right panels were $\times 200$ and $\times 400$ amplification, respectively

Table 1 Correlations of LASS2 expression with different thyroid tissues $(n=117)$

\begin{tabular}{lccc}
\hline Thyroid tissues & \multicolumn{2}{c}{ LASS2 ID score } & $P$ \\
\cline { 2 - 3 } & $\mathbf{0 - 4}$ & $\mathbf{6 - 1 2}$ & \\
\hline PTC & 37 & 23 & $0.028^{*}$ \\
Adjacent thyroid tissues & 6 & 14 & \\
nodular goiter & 16 & 21 & \\
\hline
\end{tabular}

LASS2-infected cells (28.93\%) was markedly higher compared with that of negative control cells (5.49\%) (Fig. 4a, b).

To further determine whether apoptosis induction in BCPAP cells was attributable to LASS2, a TUNEL assay was performed. Consistent with the results of Annexin$\mathrm{V}$ APC/7-AAD double-staining, the apoptosis rate of BCPAP cells treated with Adv-LASS2-GFP (30.41\%) was 
Table 2 Association between the LASS2 protein and highrisk characteristics in patients with papillary thyroid cancer $(n=60)$

\begin{tabular}{|c|c|c|c|}
\hline \multirow[t]{2}{*}{ Characteristics } & \multicolumn{2}{|c|}{ LASS2 ID score } & \multirow[t]{2}{*}{$P$} \\
\hline & $0-4$ & $6-12$ & \\
\hline Sex & & & 0.142 \\
\hline Male & 7 & 8 & \\
\hline Female & 30 & 15 & \\
\hline Age (years) & & & 0.354 \\
\hline$<45$ & 21 & 15 & \\
\hline$\geq 45$ & 16 & 8 & \\
\hline Tumor size & & & 0.067 \\
\hline$\leq 1 \mathrm{~cm}$ & 8 & 10 & \\
\hline$>1 \mathrm{~cm}$ & 29 & 13 & \\
\hline TNM Stage & & & $0.045^{*}$ \\
\hline । & 23 & 21 & \\
\hline$\|$ & 1 & 1 & \\
\hline III & 4 & 1 & \\
\hline IV & 9 & 0 & \\
\hline Location & & & 0.128 \\
\hline Unilateral & 28 & 21 & \\
\hline Bilateral & 9 & 2 & \\
\hline LNM & & & $0.001^{*}$ \\
\hline Negative & 6 & 14 & \\
\hline Positive & 31 & 9 & \\
\hline
\end{tabular}

markedly increased compared with the Adv-GFP treatment $(0.36 \%)$ or no treatment groups $(0.00 \%)$ (Fig. $4 \mathrm{c}, \mathrm{d})$.

\section{Discussion}

Sphingolipids have been identified as bioeffector molecules, controlling various aspects of cell proliferation in cancer [22]. LASS2 is a known regulator of sphingosine levels [23], and generally mediates antiproliferative responses, such as cell cycle arrest and apoptosis induction.

Rong-Hu et al. [16] reported a high correlation between LASS2 expression and Ki-67 in meningiomas, indicating their potentially similar function in tumorigenesis as proliferation-related proteins. This is in agreement with our results in human thyroid tissues, demonstrating that LASS2 was downregulated in PTC compared with adjacent non-cancerous tissues or benign disease in 97 patients. To the best of our knowledge, our study is the first to demonstrate that LASS2 was downregulated in PTC. Clinicopathological characteristics analysis revealed that the LASS2 expression level was positively correlated with TNM stage and LNM (both $P<0.05$ ). However, there were no observed correlations between LASS2 expression and patient sex, age, tumor size or location (all $P>0.05$ ).

In order to better evaluate the role of LASS2 in thyroid cancer, we detected its expression in three PTC cell lines and found that BCPAP cells expressed the lowest LASS2 compared to TPC-1 cells or K1 cells. Then we successfully overexpressed LASS2 in BCPAP cells using adenovirus vectors. Consistent with the results of IHC, our results demonstrated that LASS2 mainly localizes to the cytoplasm and nucleus, and less prominently to the cell membrane. Furthermore, overexpression of LASS2 significantly inhibited PTC cell proliferation.

Resisting cell death and sustained proliferation are considered to be the fundamental hallmarks of cancer [24]. Dysregulation of cell cycle progression subverts the dynamic balance of cell proliferation and cell death, thereby leading to cancer development $[25,26]$. Previous studies have demonstrated that the use of ceramide analogues or mimics may promote apoptosis and cause cell cycle arrest at the G0/G1 phase in cancer cells [27, 28]. Su et al. [19] reported TMSG1/LASS2 as a potential metastasis suppressor gene, involved in the induction of apoptosis and G0/G1 cell cycle arrest in 293 and $293 \mathrm{~T}$ cells. This is consistent with our in vitro data. In the present study, we confirmed that overexpression of LASS2 promoted cell apoptosis and caused G0/G1 arrest in BCPAP cells. Furthermore, we investigated the potential mechanisms involved in cell cycle arrest. The cell cycle is controlled by protein kinase complexes consisting of cyclins and cyclin-dependent kinases (CDKs) [29]. In G1 phase, D-type cyclins (D1, D2 or D3) bind to CDK4 and CDK6 and control the transition through key checkpoints, after which the cell cycle can proceed autonomously [30]. Previous studies have uncovered that the transcription factor cellular tumor antigen $\mathrm{p} 53$ regulates the expression of numerous genes involved in the cell cycle and induces cell cycle arrest [31-33]. P21, a general G1 phase cell cycle inhibitor, was the first p53-effector gene [34]. In the present study, we demonstrated that the overexpression of LASS2 resulted in the downregulation of cyclin D1 and $\mathrm{CDK} 4$, induced the expression of $\mathrm{p} 21$, and increased the expression of $\mathrm{p}-\mathrm{p} 53$, but did not significantly affect the expression of p53. Taken together, these results suggested that LASS2 overexpression induced G0/ G1 cell cycle arrest may via a p53-dependent pathway. However, p21 was also known to be regulated by p53-independent signaling pathway $[35,36]$. During 


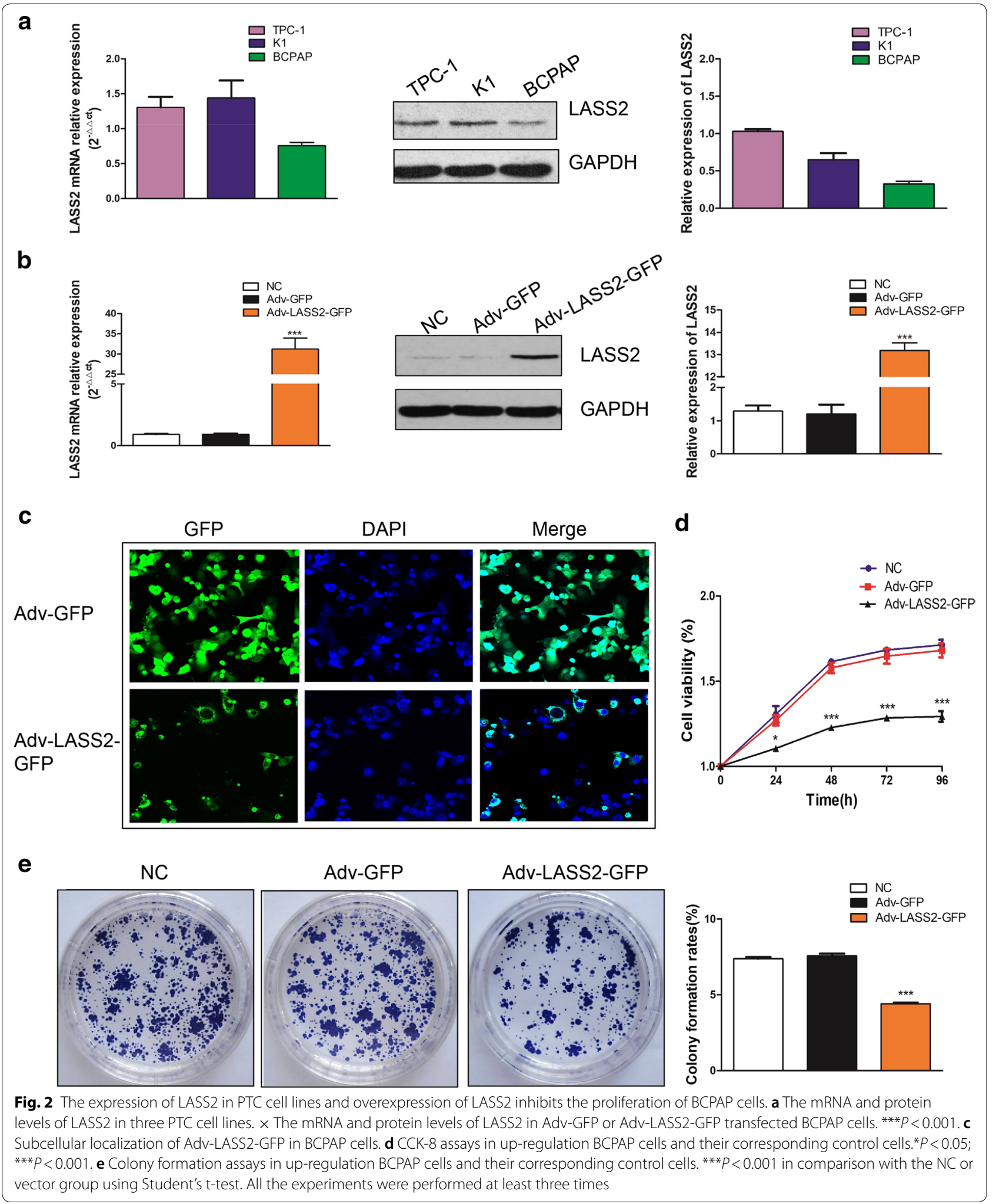



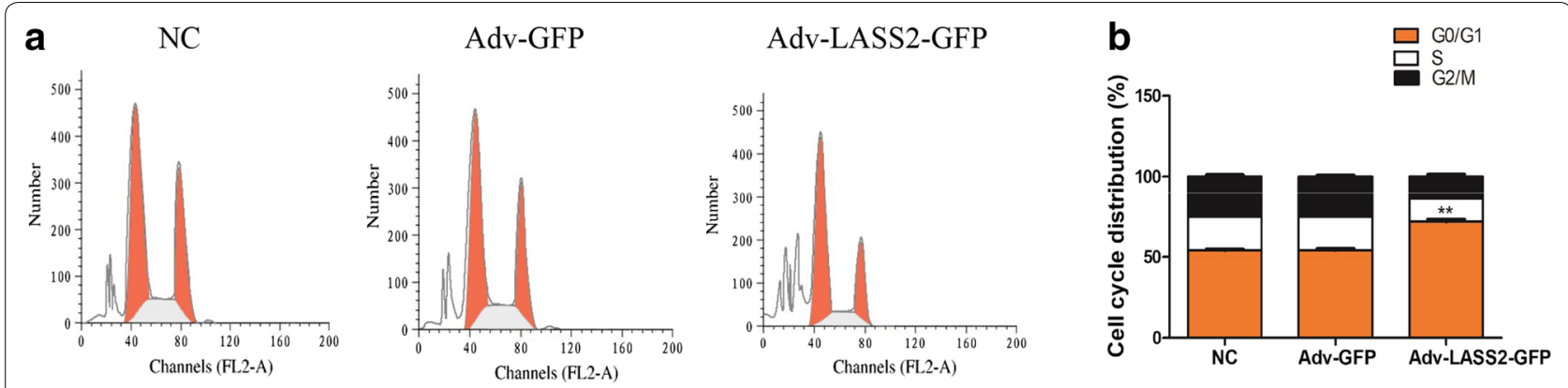

c

NC AdV-GFP AdV-LASS2-GFP
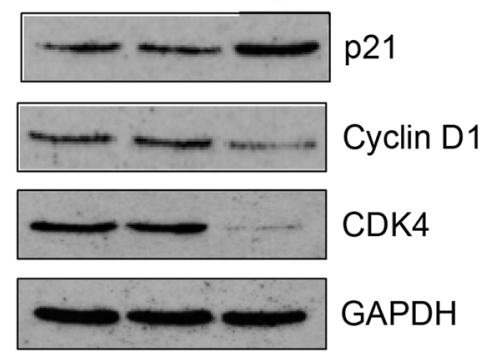

CDK4

GAPDH
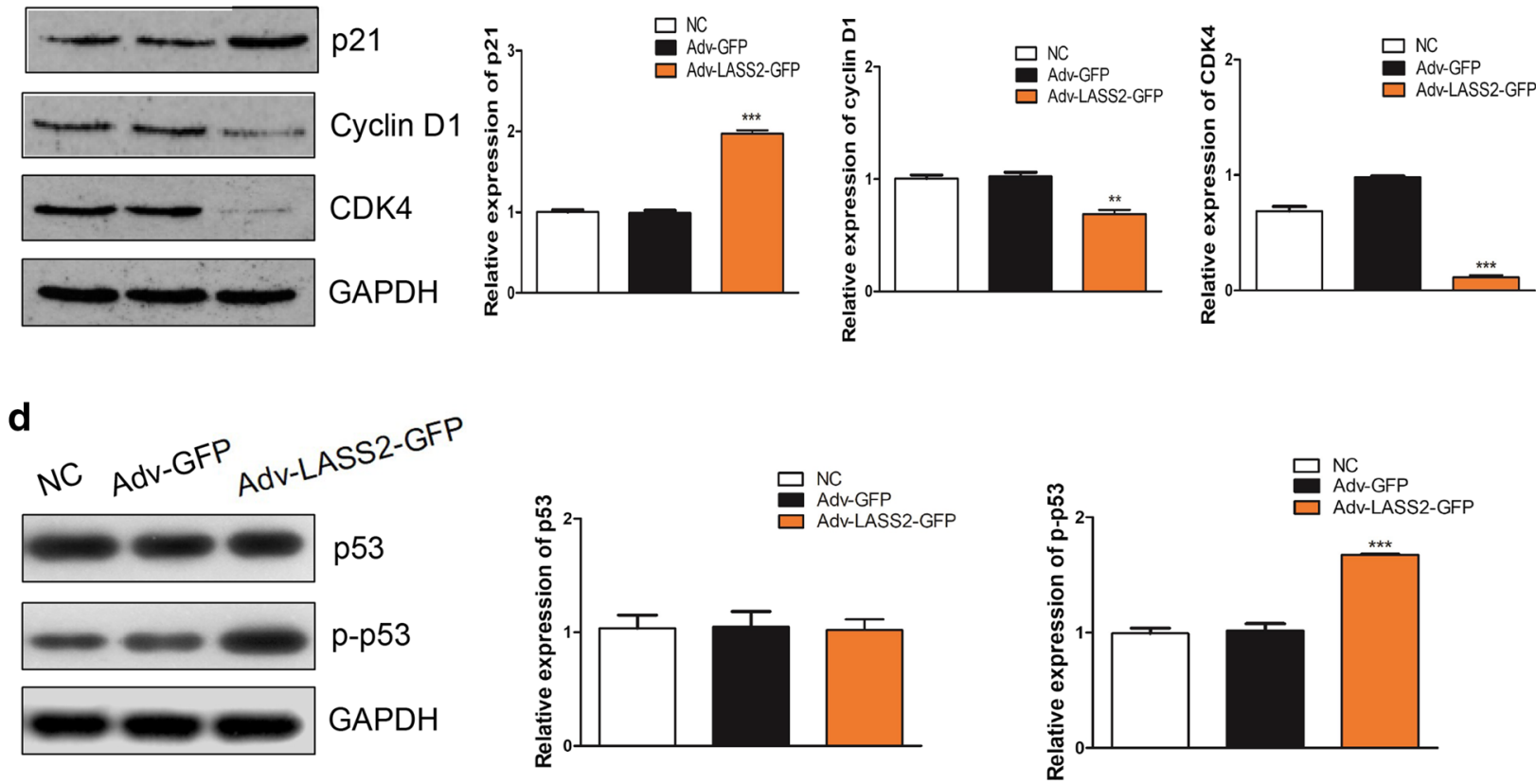

Fig. 3 Overexpression of LASS2 inhibits cell cycle progression in BCPAP cells. a and $\mathbf{b}$ Flow-cytometry analysis showed that overexpression of LASS2 significantly causes G0/G1 phase cell cycle arrest in BCPAP cells. ${ }^{* *} P<0.01$. c Effect of LASS2 on cell cycle-related gene expression was determined by western blotting. ${ }^{* *} P<0.01 ;{ }^{* *} P<0.001$. $\mathbf{d}$ Effect of LASS2 on $p$-p53 expression. ${ }^{* *} P<0.001$. All the experiments were performed at least three times

the synthesis of phospho-sphingolipids, the generation of diacylglycerol and sphingosine-1-phosphate is necessary for the G1-S transition of cell cycle [37]. Sphingolipid pathway-mediated the activation of the NF-kB [38]. Nicolae et al. [39] have identified a novel NFKBmediated mechanism of p53-independent activation of $\mathrm{p} 21$. Previous studies has showed that NF- $\mathrm{kB}$ regulated cell cycle target gene Cyclin D1 [40, 41]. Furthermore,
Schumm et al. [42] found that NF-kB stimulated the expression of Cyclin D1 and repressed the expression of $\mathrm{p} 21$, revealed a role for NF- $\mathrm{kB}$ as regulator of cell cycle. Therefore, it may be not only p53, but also NF-kB, that mediates these regulatory effects. The mechanisms underlying the role of LASS2 in BCPAP cell cycle regulation require further investigation. 


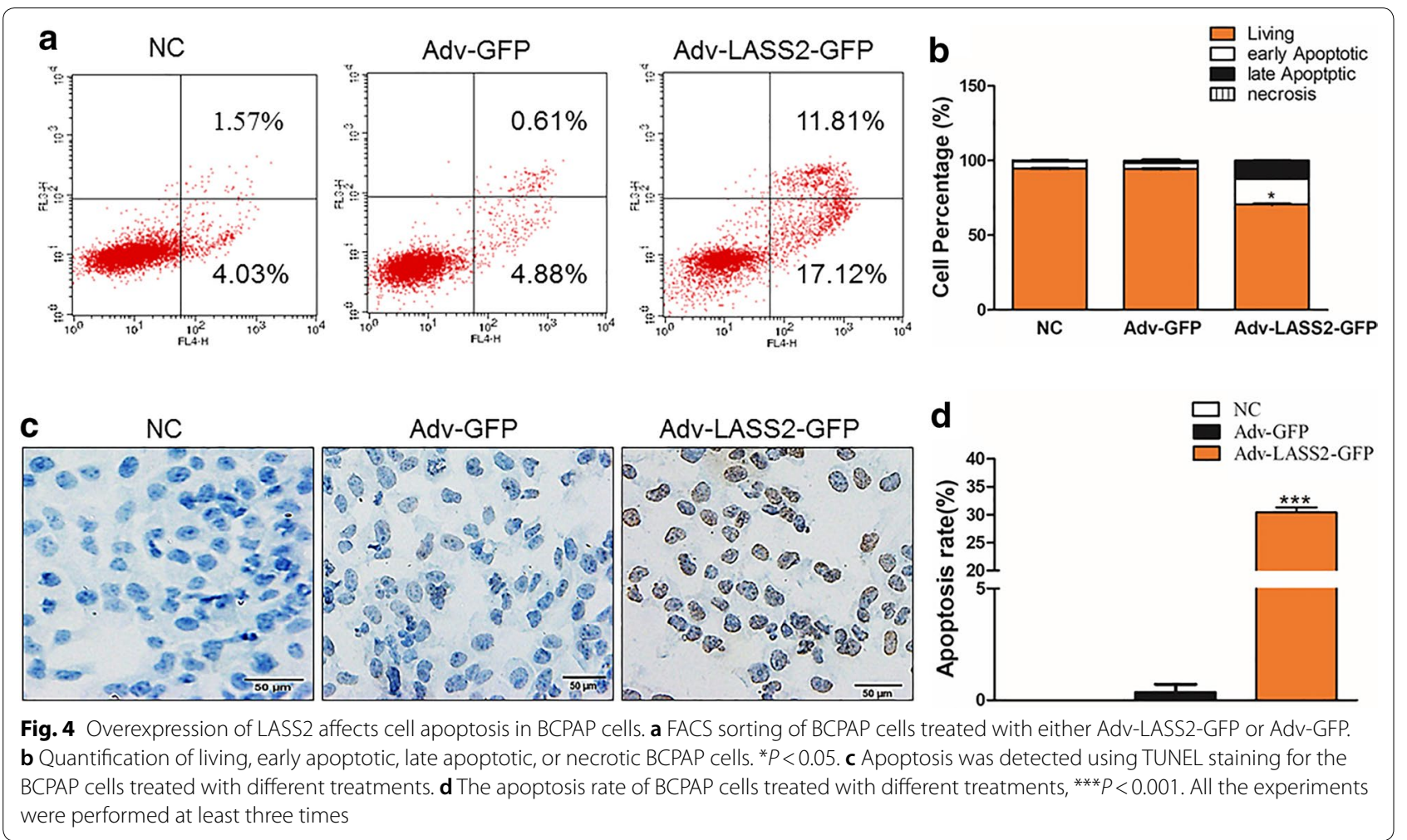

\section{Conclusion}

Our experimental data revealed that LASS2 is downregulated in PTC tissues compared with adjacent noncancerous tissues or benign diseases. To the best of our knowledge, this is the first study to demonstrate that LASS2 overexpression inhibited the proliferation ability, facilitated apoptosis and caused G0/G1 cell cycle arrest via a p53-dependent pathway in BCPAP cells. Thus, LASS2 may represent a new potential marker for the diagnosis and treatment of PTC.

\section{Abbreviations}

LASS2: LAG1 longevity-assurance homologue 2; PTC: papillary thyroid cancer; CerS2: ceramide synthase 2; CDK4: cyclin-dependent kinase 4; H\&E: hematoxylin and eosin; IHC: immunohistochemistry; ID: intensity distribution; SDS-PAGE: sodium dodecyl sulfate polyacrylamide.

\section{Authors' contributions}

FZ and YY designed the study. FZ and LLH wrote the manuscript. YY revised the manuscript. $L L H, X M C, X L Y, T L L, F G L, T Y Q$ performed experiments. LLH and YY collected the clinical data and performed data analysis. All authors read and approved the final manuscript.

\section{Author details}

${ }^{1}$ Medical Center of Breast and Thyroid Disease, Affiliated Hospital of ZunYi Medical College, Zunyi 563003, Guizhou, People's Republic of China. ${ }^{2}$ College of Laboratory Medicine, Affiliated Hospital of ZunYi Medical College, Zunyi 563003, Guizhou, People's Republic of China. ${ }^{3}$ Department of Clinical Laboratory, Affiliated Hospital of ZunYi Medical College, 149 Dalian Road, Zunyi 563003, Guizhou, People's Republic of China.

\section{Acknowledgements}

Not applicable.

\section{Competing interests}

The authors declare that they have no competing interests.

\section{Availability of data and materials}

The data supporting the conclusions of this paper are included within the manuscript.

\section{Consent for publication}

All the authors agree to the publication clause.

\section{Ethics approval and consent to participate}

The study was approved by the Ethnic Committee of the Affiliated Hospital of Zunyi Medical College, and the written informed consent was obtained from all patients.

\section{Funding}

This work was supported by grants from GuiZhou Province Science and Technology project (LH[2015]7489, [2016]1174, gzwjkj2015-1-015).

\section{Publisher's Note}

Springer Nature remains neutral with regard to jurisdictional claims in published maps and institutional affiliations.

Received: 2 August 2018 Accepted: 26 September 2018

Published online: 01 October 2018

\section{References}

1. Carling T, Udelsman R. Thyroid cancer. Annu Rev Med. 2014;65:125-37.

2. Siegel RL, Miller KD, Jemal A. Cancer statistics, 2015. CA Cancer J Clin. 2015;65(1):5-29. 
3. Davies $L$, Welch HG. Increasing incidence of thyroid cancer in the United States, 1973-2002. JAMA. 2006;295(18):2164-7.

4. Xing M. Molecular pathogenesis and mechanisms of thyroid cancer. Nat Rev Cancer. 2013;13(3):184-99.

5. Loo E, Khalili P, Beuhler K, Siddiqi I, Vasef MA. BRAF V600E mutation across multiple tumor types: correlation between DNA-based sequencing and mutation-specific immunohistochemistry. Appl Immunohistochem Mol Morphol. 2017. https://doi.org/10.1097/PAl.0000000000000516.

6. Celestino R, Nome T, Pestana A, Hoff AM, Gonçalves AP, Pereira L, Cavadas B, Eloy C, Bjøro T, Sobrinho-Simões M, Skotheim RI, Soares P. CRABP1, C1QL1 and LCN2 are biomarkers of differentiated thyroid carcinoma, and predict extrathyroidal extension. BMC Cancer. 2018;18(1):68.

7. Razavi SA, Modarressi MH, Yaghmaei P, Tavangar SM, Hedayati M. Circulating levels of PTEN and KLLN in papillary thyroid carcinoma: can they be considered as novel diagnostic biomarkers. Endocrine. 2017;57(3):428-35.

8. Krishnamurthy A, Ramshankar V, Murherkar K, Vidyarani S, Raghunandhan GC, Das A, Desai PB, Albert K. Role and relevance of BRAF mutations in risk stratifying patients of papillary thyroid cancers along with a review of literature. Indian J Cancer. 2017;54(1):372-8.

9. Pan H, Qin WX, Huo KK, Wan DF, Yu Y, Xu ZG, Hu QD, Gu KT, Zhou XM, Jiang HQ, Zhang PP, Huang Y, Li YY, Gu JR. Cloning, mapping, and characterization of a human homologue of the yeast longevity assurance gene LAG1. Genomics. 2001;77(1-2):58-64.

10. Seitz AP, Grassmé H, Edwards MJ, Pewzner-Jung Y, Gulbins E. Ceramide and sphingosine in pulmonary infections. Biol Chem. 2015;396(6-7):611-20.

11. Ma C, Liu Y, Zheng J, Fang W, You J, Wang J, Cui X, Wu B. Identification of tumor metastasis related gene TMSG-1 by mRNA differential display. Sci China C Life Sci. 2002;45(5):553-60

12. Wang $H$, Zuo Y, Ding M, Ke C, Yan R, Zhan H, Liu J, Wang W, Li N, Wang J. LASS2 inhibits growth and invasion of bladder cancer by regulating ATPase activity. Oncol Lett. 2017;13(2):661-8.

13. Xu X, Liu B, Zou P, Zhang Y, You J, Pei F. Silencing of LASS2/TMSG1 enhances invasion and metastasis capacity of prostate cancer cell. J Cell Biochem. 2014;115(4):731-43.

14. Mei F, You J, Liu B, Zhang M, Liu J, Zhang B, Pei F. LASS2/TMSG1 inhibits growth and invasion of breast cancer cell in vitro through regulation of vacuolar ATPase activity. Tumour Biol. 2015;36(4):2831-44.

15. Imgrund S, Hartmann D, Farwanah H, Eckhardt M, Sandhoff R, Degen J, Gieselmann V, Sandhoff K, Willecke K. Adult ceramide synthase 2 (CERS2)deficient mice exhibit myelin sheath defects, cerebellar degeneration and hepatocarcinomas. J Biol Chem. 2009:284(48):33549-60.

16. Ke RH, Wang Y, Mao Y, Zhang J, Xiong J. Decreased expression of LASS2 is associated with worse prognosis in meningiomas. J Neurooncol. 2014;118(2):369-76

17. Wang H, Wang J, Zuo Y, Ding M, Yan R, Yang D, Ke C. Expression and prognostic significance of a new tumor metastasis suppressor gene LASS2 in human bladder carcinoma. Med Oncol. 2012;29(3):1921-7.

18. Jin $H$, Wang $C$, Gu D, Zhang $Y$, Fan $S$, Xing $S$, Wang $H$, Ruan $H$, Yang $C$, Lv $Y$, Feng $\mathrm{H}$, Yao M, Qin W. Liver-specific deletion of LASS2 delayed regeneration of mouse liver after partial hepatectomy. Biochem Biophys Res Commun. 2017:493(3):1176-83.

19. Su J, Yu W, Gong M, You J, Liu J, Zheng J. Overexpression of a novel tumor metastasis suppressor gene TMSG1/LASS2 induces apoptosis via a caspase-dependent mitochondrial pathway. J Cell Biochem. 2015;116(7):1310-7

20. Fan $\mathrm{S}$, Niu $Y$, Tan N, Wu Z, Wang Y, You H, Ke R, Song J, Shen Q, Wang W, Yao G, Shu H, Lin H, Yao M, Zhang Z, Gu J, Qin W. LASS2 enhances chemosensitivity of breast cancer by counteracting acidic tumor microenvironment through inhibiting activity of V-ATPase proton pump. Oncogene. 2013;32(13):1682-90.

21. Turkekul K, Colpan RD, Baykul T, Ozdemir MD, Erdogan S. Esculetin inhibits the survival of human prostate cancer cells by inducing apoptosis and arresting the cell cycle. J Cancer Prev. 2018:23(1):10-7.
22. Ponnusamy $S$, Meyers-Needham M, Senkal CE, Saddoughi SA, Sentelle $D$, Selvam SP, Salas A, Ogretmen B. Sphingolipids and cancer: ceramide and sphingosine-1-phosphate in the regulation of cell death and drug resistance. Future Oncol. 2010;6(10):1603-24.

23. Rieck M, Kremser C, Jobin K, Mettke E, Kurts C, Gräler M, Willecke K, Kolanus W. Ceramide synthase 2 facilitates S1P-dependent egress of thymocytes into the circulation in mice. Eur J Immunol. 2017:47(4):677-84.

24. Hanahan D, Weinberg RA. Hallmarks of cancer: the next generation. Cell. 2011;144(5):646-74

25. Ucker DS, Levine JS. Exploitation of apoptotic regulation in cancer. Front Immunol. 2018:9:241.

26. Evan Gl, Vousden KH. Proliferation, cell cycle and apoptosis in cancer. Nature. 2001;411(6835):342-8.

27. Rossi MJ, Sundararaj K, Koybasi S, Phillips MS, Szulc ZM, Bielawska A, Day TA, Obeid LM, Hannun YA, Ogretmen B. Inhibition of growth and telomerase activity by novel cationic ceramide analogs with high solubility in human head and neck squamous cell carcinoma cells. Otolaryngol Head Neck Surg. 2005;132(1):55-62.

28. Senkal CE, Ponnusamy S, Rossi MJ, Sundararaj K, Szulc Z, Bielawski J, Bielawska A, Meyer M, Cobanoglu B, Koybasi S, Sinha D, Day TA, Obeid LM, Hannun YA, Ogretmen B. Potent antitumor activity of a novel cationic pyridinium-ceramide alone or in combination with gemcitabine against human head and neck squamous cell carcinomas in vitro and in vivo. J Pharmacol Exp Ther. 2006;317(3):1188-99.

29. Santamaria D, Ortega S. Cyclins and CDKS in development and cancer: lessons from genetically modified mice. Front Biosci. 2006;11:1164-88.

30. Mullany LK, White $P$, Hanse EA, et al. Distinct proliferative and transcriptional effects of the D-type cyclins in vivo. Cell Cycle. 2008;7(14):2215-24.

31. Mo J, Lin M, He B, et al. Recombinant human adenovirus-p53 improves the outcome of mid-late stage pancreatic cancer via arterial infusion. Oncol Lett. 2017:14(6):6829-32.

32. Smits VA. EDD induces cell cycle arrest by increasing p53 levels. Cell Cycle. 2012;11(4):715-20.

33. Kastan MB, Canman CE, Leonard CJ. P53, cell cycle control and apoptosis: implications for cancer. Cancer Metastasis Rev. 1995;14(1):3-15.

34. Wang Y, Qiu C, Lu N, et al. FOXD1 is targeted by miR-30a-5p and miR200a-5p and suppresses the proliferation of human ovarian carcinoma cells by promoting p21 expression in a p53-independent manner. Int J Oncol. 2018;52(6):2130-42.

35. Huang X, Qiao Y, Zhou Y, et al. Ureaplasma spp. lipid-associated membrane proteins induce human monocyte U937 cell cycle arrest through p53-independent p21 pathway. Int J Med Microbiol. 2018:308:819-28.

36. Huang $S$, Li Y, Yuan X, et al. The UbL-UBA Ubiquilin4 protein functions as a tumor suppressor in gastric cancer by p53-dependent and p53-independent regulation of p21. Cell Death Differ. 2018. https://doi. org/10.1038/s41418-018-0141-4.

37. Cerbón J, Baranda-Avila N, Falcón-Muñoz A, Camacho-Arroyo I, Cerbón M. Sphingolipid synthesis and role in uterine epithelia proliferation. Reproduction. 2018;156(2):173-83.

38. Oh E, Yun M, Kim SK, et al. Palmitate induces COX-2 expression via the sphingolipid pathway-mediated activation of NF-KB, p38, and ERK in human dermal fibroblasts. Arch Dermatol Res. 2014;306(4):339-45.

39. Nicolae CM, O'Connor MJ, Constantin D, Moldovan GL. NFKB regulates p21 expression and controls DNA damage-induced leukemic differentiation. Oncogene. 2018;37:3647-56.

40. Ledoux AC, Perkins ND. NF-KB and the cell cycle. Biochem Soc Trans. 2014:42(1):76-81.

41. Barré B, Perkins ND. A cell cycle regulatory network controlling NFkappaB subunit activity and function. EMBO J. 2007;26(23):4841-55.

42. Schumm K, Rocha S, Caamano J, Perkins ND. Regulation of p53 tumour suppressor target gene expression by the p52 NF-kappaB subunit. EMBO J. 2006:25(20):4820-32. 